\title{
Dietas imunomoduladoras em pacientes com câncer do trato gastrointestinal: Revisão integrativa
}

\author{
Immunomodulatory diets in patients with gastrointestinal tract cancer: Integrative \\ review
}

Thais Aline de Sousa Feitosa Guimarães ${ }^{1}$

Orcid: https://orcid.org/0000-0001-5748-4323
Luciana Carla dos Santos Silva ${ }^{2}$

Orcid: https://orcid.org/0000-0002-4034-6503

\author{
Ana Lina de Carvalho Cunha Sales ${ }^{3}$ \\ Orcid: https://orcid.org/0000-0001-5951-5437
}

\begin{abstract}
Resumo
Introdução: $O$ paciente oncológico sofre uma série de alterações metabólicas e nutricionais em decorrência da doença e dos tratamentos utilizados. Estudos revelam que a suplementação com fórmulas enterais e dietas imunomoduladoras com nutrientes específicos podem melhorar o estado nutricional, o sistema imunológico e agir na modulação da resposta inflamatória. Objetivo: Analisar através da literatura o efeito de dietas imunomoduladoras em pacientes cirúrgicos com câncer do trato gastrointestinal. Materiais e métodos: Trata-se de um estudo de revisão integrativa da literatura, utilizando artigos indexados nas bases de dados BVS, PubMed e SciELO através dos descritores: "nutrição enteral", "cirurgia", "neoplasia gastrointestinal", "arginina", “ácidos graxos ômega-3" e "glutamina”, combinados ao operador booleano "AND", disponíveis nos idiomas português, inglês e espanhol, publicados nos últimos 10 anos. Resultados: Foram encontrados no total 236 artigos e 11 compuseram a amostra após aplicação dos critérios de inclusão. Estudos demonstram que a suplementação com dietas imunomoduladoras em pacientes cirúrgicos de câncer do trato gastrointestinal é eficaz, visto que auxiliam na melhora da resposta inflamatória, imunológica, e no estado nutricional, prevenindo a perda de peso, diminuindo as complicações pós-operatórias, possibilitando uma melhor recuperação e redução do tempo de permanência hospitalar. Conclusões: A terapia nutricional com dietas imunomoduladoras contribui positivamente no tratamento, recuperação e redução de complicações em pacientes oncológicos. Sugere-se a realização de novos estudos para promoção de mais evidências científicas necessárias para estabelecimento de protocolos de suplementação para casos cirúrgicos de pacientes com neoplasias do trato gastrointestinal..
\end{abstract}

Palavras-chave: imunomodulação; nutrição enteral; neoplasias gastrointestinais.

\begin{abstract}
Introduction: The cancer patient undergoes a series of metabolic and nutritional changes due to the disease and the treatments used. Studies reveal that supplementation with enteral formulas and immunomodulatory diets with specific nutrients can improve nutritional status, the immune system and act in the modulation of the inflammatory response. Objective: Analyzing through the literature the effect of immunomodulatory diets in surgical patients with cancer of the gastrointestinal tract. Materials and methods: This is an integrative literature review study, using articles indexed in the VHL, PubMed and SciELO databases through the descriptors: "enteral nutrition", "surgery", "gastrointestinal neoplasia", "arginine", "Omega-3 fatty acids" and "glutamine", combined with the Boolean operator "AND", available in Portuguese, English and Spanish, published in the last 10 years. Results: A total of 236 articles were found and 11 made up the sample after applying the inclusion criteria. Studies show that supplementation with immunomodulatory diets in surgical patients with cancer of the
\end{abstract}

\footnotetext{
${ }^{1}$ Centro Universitário Santo Agostinho. E-mail: tatahaline_@hotmail.com

${ }^{2}$ Centro Universitário Santo Agostinho. E-mail: lucianacarlasilva2114@gmail.com

${ }^{3}$ Universidade Federal do Piauí. E-mail: ana.lina123@gmail.com
} 
gastrointestinal tract is effective, since they help in improving the inflammatory and immunological response, and in the nutritional status, preventing weight loss, reducing postoperative complications, enabling a better recovery and reducing the length of hospital stay. Conclusions: Nutritional therapy with immunomodulatory diets contributes positively to the treatment, recovery and reduction of complications in cancer patients. It is suggested that further studies be carried out to promote more scientific evidence necessary to establish supplementation protocols for surgical cases of patients with neoplasms of the gastrointestinal tract.

Keywords: immunomodulation; enteral nutrition; gastrointestinal neoplasms.

\section{Introdução}

O câncer atualmente é considerado o principal problema de saúde pública em todo o mundo, e está em quarto lugar no ranking como uma das principais causas de morte prematura na maioria dos países. Sua incidência e mortalidade vêm aumentando pelo mundo, e estimativas apontam um aumento de 620 mil novos casos a cada ano até $2022^{1}$.

O câncer do trato gastrointestinal aparece como a quarta causa mais comum, e o câncer de estômago como o segundo, em termos de mortalidade por tumores malignos. Por outro lado, a sobrevida para câncer colorretal é considerada boa, se a doença for diagnosticada em estágio inicial $^{2}$.

O paciente oncológico sofre uma série de alterações metabólicas e nutricionais em decorrência da doença e dos tratamentos utilizados. Essas alterações podem contribuir para a desnutrição proteico-calórica, o que impacta de forma negativa na terapêutica da doença, pois o déficit no estado nutricional associa-se à diminuição da resposta ao tratamento e da qualidade de vida do paciente. $\mathrm{O}$ surgimento e a gravidade da desnutrição estão relacionados a vários fatores, tais como: idade, tipo de câncer, estágio da doença e tipo de tratamento ${ }^{3}$.

No câncer gastrointestinal, em que a ingestão oral alimentar é insuficiente e a função intestinal geralmente é prejudicada, a incidência de desnutrição em pacientes oncológicos varia de $40 \%$ a $80 \%$, e por isso recomenda-se a suplementação nutricional para suprir as necessidades energéticas, visto que o estado nutricional de pacientes hospitalizados reflete diretamente sobre a evolução clínica ${ }^{4}$.

Estudos realizados nos últimos anos revelam melhora do estado nutricional e sistema imunológico através do uso de fórmulas enterais as quais fornecem os nutrientes necessários e adequados, mesmo que ainda sejam procuradas novas estratégias terapêuticas que possam modificar a resposta metabólica causada pelo estresse ${ }^{5}$.

$\mathrm{O}$ uso de dietas imunomoduladoras com nutrientes específicos, como: arginina, glutamina, ácidos graxos dentre outros, podem ter ação direta ou indireta no sistema imune, na modulação da resposta inflamatória e auxiliar no tratamento de pacientes com desnutrição, caquexia e câncer ${ }^{4,6}$.

A recomendação da European Society of Parenteral and Enteral Nutrition (ESPEN) é de que a nutrição enteral com fórmulas imunomoduladoras seja utilizada tanto no pré-operatório quanto no pós em pacientes cirúrgicos, independente do risco nutricional do indivíduo, no período de cinco a sete dias, podendo estender-se até 14 dias em casos de desnutrição, visando reduzir o risco do surgimento de complicações. Em neoplasias do trato gastrointestinal a recomendação para utilização de fórmulas imunomoduladoras em pacientes submetidos a cirurgias eletivas possui alto grau de evidência científica de nível A, mostrando-se benéfica para cirurgias desse tipo ${ }^{5,7}$.

A imunonutrição é fator chave na fase pré-operatória, melhorando consequentemente o pós-operatório do paciente. Nos últimos anos as formulações enriquecidas com imunonutrientes 
trouxeram um novo sentido ao processo de recuperação do paciente hospitalizado após uma grande cirurgia intestinal. Esses nutrientes têm função de modular a resposta imune e estimular a síntese de proteínas, contribuindo para o prognóstico favorável do paciente ${ }^{8}$.

Diante do exposto, o objetivo do presente estudo foi analisar, através da literatura científica, o efeito de dietas imunomoduladoras em pacientes cirúrgicos com câncer do trato gastrointestinal.

\section{Materiais e Métodos}

\section{Amostra e tipo de estudo}

Trata-se de um estudo de revisão integrativa da literatura, que corresponde a um método amplo que inclui estudos de diferentes abordagens metodológicas, possibilitando assim, a síntese e análise do conhecimento produzido ${ }^{9}$.

\section{Delineamento da pesquisa}

A revisão foi realizada no período de maio a julho de 2020 com as seguintes etapas: formulação da questão norteadora; seleção de artigos com base no título e ano de publicação; seleção dos artigos por resumos; seleção pelo texto na íntegra e logo após, extração dos dados dos estudos incluídos; avaliação e interpretação dos resultados; e apresentação da revisão do conhecimento produzido.

Para formulação da questão norteadora utilizou-se a estratégia PICO, que para Santos, Pimenta e Nobre ${ }^{10}$ significa um acrônimo, definindo-se como população "pacientes com câncer do trato gastrointestinal", fenômeno de interesse "uso de dietas imunomoduladoras", contexto "pré ou pós-cirúrgicos de câncer do trato gastrointestinal" e desfecho "melhora no estado nutricional, resposta imunológica e inflamatória", resultando na pergunta: "Quais as evidências científicas acerca dos efeitos de dietas imunomoduladoras em pacientes cirúrgicos com câncer do trato gastrointestinal?".

\section{Critérios de Inclusão e Exclusão}

Foram incluídos no estudo, artigos originais, com seres humanos, ensaios clínicos, estudos clínicos, publicados no período de 2010 a 2020, que estivessem disponíveis na íntegra e que abordassem: nutrição enteral, cirurgia, câncer/neoplasia gastrointestinal, arginina, ácidos graxos ômega-3 e glutamina, nos idiomas português, inglês e espanhol. Foram excluídos estudos fora da temática, estudos com animais, metanálises e estudos de revisão.

\section{Procedimentos}

Para a busca de artigos, as bases de dados utilizadas foram a Biblioteca Virtual de Saúde (BVS), PubMed e Scientifc Eletronic Library Online (SciELO), através dos descritores: nutrição enteral, cirurgia, câncer gastrointestinal, arginina, ácidos graxos ômega-3 e glutamina, de acordo com os Decs e MeSH, que combinados ao operador booleano (AND), resultou na seguinte estratégia de busca: "nutrição enteral and cirurgia and câncer gastrointestinal and glutamina";“ nutrição enteral and cirurgia and câncer gastrointestinal and arginina" e " nutrição enteral and cirurgia and câncer gastrointestinal and ácidos graxos omega3" bem como suas traduções para o inglês e espanhol para obtenção de melhores resultados.

\section{Resultados}

A busca totalizou 236 produções e após a aplicação dos filtros, 50 artigos foram selecionados dos quais foram excluídos pelo título e leitura do resumo 29 artigos, e após a leitura na íntegra 10. Desse modo, 11 artigos compuseram a amostra e foram analisados. A figura 1 (Prisma Flow) mostra o percurso realizado para seleção dos estudos, conforme base de dados consultada. 
Figura 1 - Fluxograma da seleção dos artigos encontrados e selecionados (Prisma Flow).

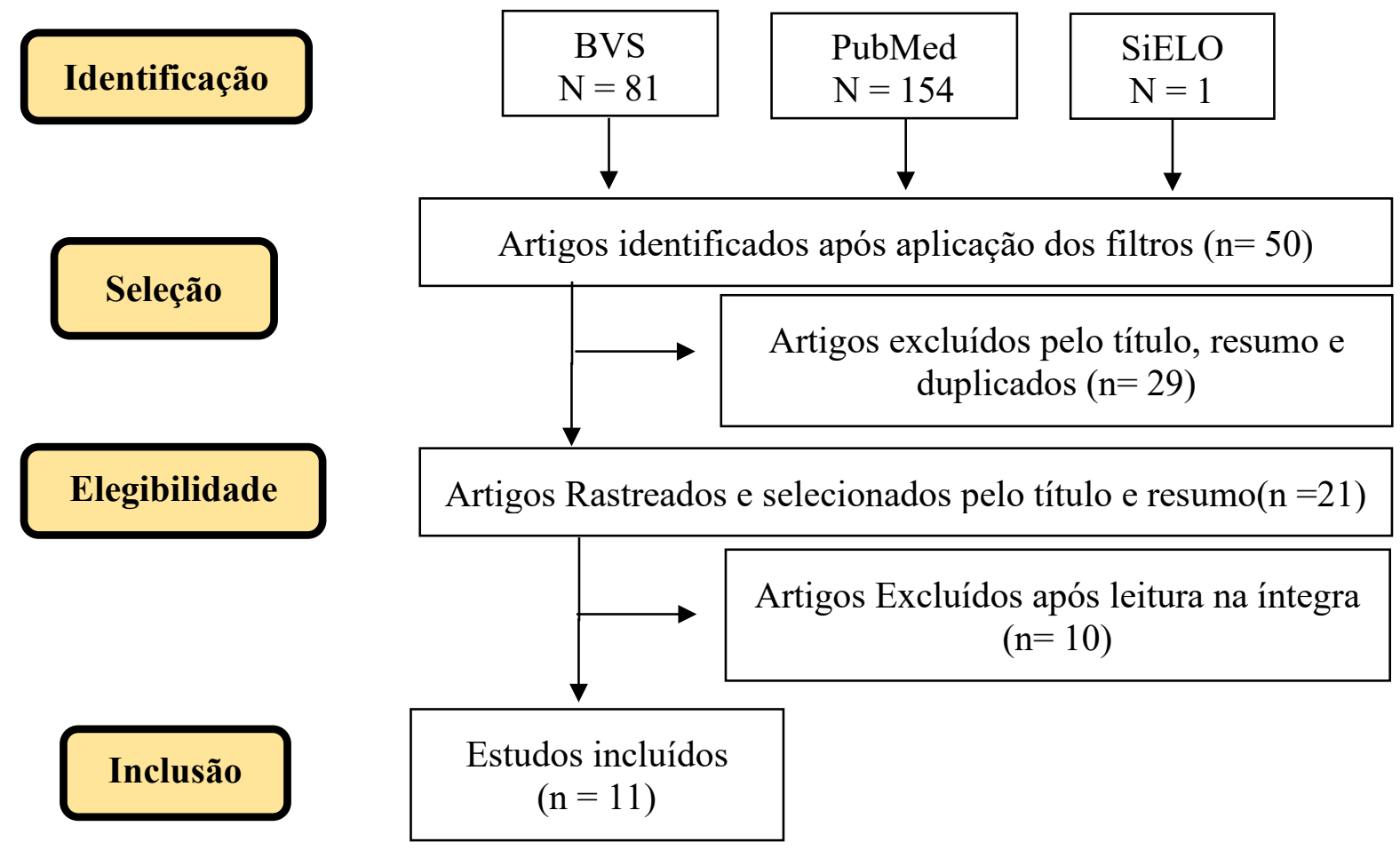

Fonte: Guimarães, Silva e Sales (2020), adaptado de Moher, Liberati, Tetzlaff e Altman ${ }^{11}$.

Todos os artigos selecionados para análise tratam-se de estudos de intervenção. A extração dos dados foi realizada com auxílio de instrumento próprio e os artigos selecionados foram organizados no quadro 1 de acordo com as variáveis: autores, ano de publicação, objetivos, amostra, conteúdo da dieta, suplementação e principais resultados e conclusões.
Os estudos foram avaliados quanto à suplementação de nutrientes imunomoduladores glutamina, arginina e ômega 3 em pacientes com neoplasias do trato gastrointestinal. As amostras dos estudos variaram de 20 a 326 pacientes cirúrgicos com idades acima de 18 anos. 
Quadro 1. Síntese das principais características dos artigos incluídos na revisão. Teresina, Brasil, 2020.

\begin{tabular}{|c|c|c|c|c|c|c|}
\hline $\begin{array}{c}\text { Autor/ ano } \\
\text { de } \\
\text { publicação }\end{array}$ & Tipo de estudo & Objetivo & Amostra & $\begin{array}{c}\text { Conteúdo da } \\
\text { dieta }\end{array}$ & Suplementação & $\begin{array}{c}\text { Principais resultados/ } \\
\text { conclusões }\end{array}$ \\
\hline $\begin{array}{l}\text { Ma C, et al., } \\
(2018)^{4}\end{array}$ & $\begin{array}{l}\text { Estudo } \\
\text { prospectivo, } \\
\text { randomizado, } \\
\text { duplo-cego }\end{array}$ & $\begin{array}{l}\text { Determinar se uma dieta rica } \\
\text { em nutrientes e enriquecida } \\
\text { com nutrientes moduladores } \\
\text { do sistema imunológico pode } \\
\text { melhorar o estado nutricional } \\
\text { e reduzir a infecção pós- } \\
\text { operatória e a supressão } \\
\text { imune induzida pela cirurgia } \\
\text { em pacientes com câncer } \\
\text { gástrico ou GIST submetidos } \\
\text { à cirurgia de grande porte. }\end{array}$ & $\begin{array}{l}34 \text { pacientes com } \\
\text { adenocarcinoma } \\
\text { gástrico ou tumor } \\
\text { estromal } \\
\text { gastrointestinal } \\
\text { (GIST) submetidos à } \\
\text { cirurgia curativa } \\
\text { eletiva } \\
\text { Grupo suplementado: } \\
\text { (n=17) } \\
\text { Grupo controle: } \\
(\mathrm{n}=17)\end{array}$ & $\begin{array}{l}\text { Glutamina, } \\
\text { arginina e óleo } \\
\text { de peixe }\end{array}$ & $\begin{array}{l}\text { Grupo suplementado: dieta } \\
\text { comum mais } 400 \mathrm{ml} / \text { dia de } 3-5 \\
\text { dias antes da cirurgia. No } 4^{\circ} \text { dia } \\
\text { de pós-operatório, dieta } \\
\text { semilíquida mais } 400 \mathrm{ml} / \text { dia da } \\
\text { dieta intervencionista e do } 5^{\circ} \text { ao } \\
14^{\circ} \text { dia ou alta, } 1200 \mathrm{ml} / \text { dia da } \\
\text { dieta intervencionista mais dieta } \\
\text { oral suave. } \\
\text { Grupo controle: recebeu dieta } \\
\text { padrão } 3 \text { dias antes da cirurgia } \\
\text { até } 14^{\circ} \text { dia de pós-operatório ou } \\
\text { alta. }\end{array}$ & $\begin{array}{l}\text { Não foram observadas } \\
\text { diferenças significativas entre } \\
\text { os grupos nos parâmetros } \\
\text { laboratoriais e inflamatórios, } \\
\text { ou em sua alteração líquida, } \\
\text { antes e após o tratamento. A } \\
\text { nutrição enteral enriquecida } \\
\text { com nutrientes } \\
\text { imunomoduladores não teve } \\
\text { efeito de imunomodulação } \\
\text { proeminente em compacação } \\
\text { com a nutrição enteral padrão. }\end{array}$ \\
\hline $\begin{array}{l}\text { Liu H, et al., } \\
(2012)^{12}\end{array}$ & $\begin{array}{l}\text { Estudo } \\
\text { randomizado } \\
\text { controlado }\end{array}$ & $\begin{array}{l}\text { Determinar se a nutrição } \\
\text { enteral imune (EN) foi eficaz } \\
\text { no estado nutricional, na } \\
\text { função imunológica, nos } \\
\text { resultados cirúrgicos e nos } \\
\text { dias de internação após } \\
\text { gastrectomia total em } \\
\text { pacientes com câncer } \\
\text { gástrico avançado (AGC) }\end{array}$ & 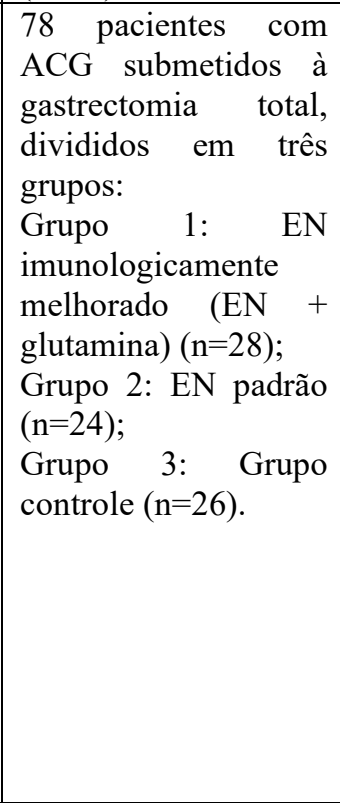 & $\begin{array}{l}\text { Glutamina, } \\
\text { arginina }\end{array}$ & $\begin{array}{l}\text { Grupo 1: EN padrão enriquecida } \\
\text { com Gln }(12,5 \mathrm{~g} / \mathrm{L}) \text { e arginina } \\
(9,0 \mathrm{~g} / \mathrm{L}) ; \\
\text { Grupo } 2 \text { : EN padrão de } \\
500 \mathrm{ml} / \text { frasco }(20,0 \mathrm{~g} \text { de } \mathrm{PT}, 9,5 \mathrm{~g} \\
\text { de } \mathrm{LIP}, 61,5 \mathrm{~g} \text { de } \mathrm{CHO}, 7,5 \mathrm{~g} \text { de } \\
\text { fibra, } 3 \mathrm{~g} \text { de minerais e } 0,15 \mathrm{~g} \text { de } \\
\text { vitaminas), fornecendo } 500 \mathrm{kcal} \\
\text { do total de energia. } \\
\text { Grupo 3: receberam apoio } \\
\text { nutricional de CHO (5\% e } 10 \% \\
\text { de glicose), enquanto a ingestão } \\
\text { de alimentos líquidos e } \\
\text { semilíquidos fosse administrada. }\end{array}$ & $\begin{array}{l}\text { Os grupos } 1 \text { e } 2 \text { tiveram um } \\
\text { início mais rápido de flatos } \\
\text { menor tempo de internação do } \\
\text { que o grupo controle. No } 12^{\circ} \\
\text { dia de pós-operatório, os níveis } \\
\text { séricos de pt, albumina, } \\
\text { proalbumina e transferrina dos } \\
\text { grupos } 1 \text { e } 2 \text { foram } \\
\text { significativamente maiores que } \\
\text { do grupo } 3 \text {. As células T CD } 4^{+} \text {, } \\
\text { NK, os níveis de IgM e IgG do } \\
\text { grupo } 1 \text { aumentaram e foram } \\
\text { significativamente mais altos } \\
\text { do que antes da operação, bem } \\
\text { como nos grupos } 2 \text { e } 3 \text {. } \\
\text { A EN imune-aprimorada pode } \\
\text { melhorar o estado nutricional e } \\
\text { função imune dos pacientes } \\
\text { com AGC após gastrectomia } \\
\text { total. }\end{array}$ \\
\hline
\end{tabular}




\begin{tabular}{|c|c|c|c|c|c|c|}
\hline $\begin{array}{l}\text { Abe T, et al., } \\
(2018)^{13}\end{array}$ & $\begin{array}{l}\text { Estudo } \\
\text { observacional }\end{array}$ & $\begin{array}{llr}\text { Explorar o impacto da } & \text { o } \\
\text { cirurgia peri-operatória com } \\
\text { administração de GFO no } \\
\text { pós-operatório de } & \text { curto } \\
\text { prazo, desfechos } & \text { e } \\
\text { complicações } & \text { pós- } \\
\text { operatórias após tratamento } \\
\text { de } & \text { esofagectomia } \\
\text { transtorácica radical em } \\
\text { pacientes com câncer de } \\
\text { esôfago torácico. }\end{array}$ & $\begin{array}{l}326 \text { pacientes com } \\
\text { câncer de esôfago, } \\
\text { Grupo suplementado } \\
\text { (n=189): receberam } \\
\text { tratamento } \\
\text { perioperatório com } \\
\text { GFO (glutamina, } \\
\text { fibra } \\
\text { oligossacarídeo). } \\
\text { Grupo controle } \\
\text { (n=137): não recebeu. }\end{array}$ & $\begin{array}{l}\text { Glutamina, fibra } \\
\text { e } \\
\text { oligossacarídeo }\end{array}$ & $\begin{array}{l}\text { IMPACT }(750 \mathrm{ml} / \mathrm{dia}) \text { para } \\
\text { todos os pacientes por } 5 \text { dias } \\
\text { antes da cirurgia. } \\
\text { Grupo suplementado: receberam } \\
\text { GFO a três embalagens/dia via } \\
\text { oral ou transluminal por cinco } \\
\text { dias no pré, e no pós cirúrgico de } \\
4 \mathrm{~h} \text { após a cirurgia } 250 \mathrm{ml} / \mathrm{dia} \text { e } \\
\text { aumentou gradualmente para } \\
1500 \mathrm{ml} / \text { dia } 4^{\circ} \text { dia. } \\
\text { Suplementação até } 14^{\circ} \text { dia. }\end{array}$ & $\begin{array}{l}\text { A duração da SIRS foi } \\
\text { significativamente menor no } \\
\text { grupo GFO comparado ao } \\
\text { grupo controle, e o valor de } \\
\text { PCR foi significativamente } \\
\text { menor no grupo GFO do que } \\
\text { no grupo controle no } 2^{\circ} \text { dia do } \\
\text { pós-operatório. } \\
\text { O uso Peri operatório da } \\
\text { suplementação enteral com } \\
\text { glutamina, fibra e } \\
\text { oligossacarídeo provavelmente } \\
\text { contribui para a redução do } \\
\text { estresse cirúrgico precoce após } \\
\text { uma esofagectomia. }\end{array}$ \\
\hline $\begin{array}{l}\text { Kleck S, et } \\
\text { al., }(2016)^{14}\end{array}$ & $\begin{array}{l}\text { Ensaio clínico } \\
\text { randomizado }\end{array}$ & $\begin{array}{l}\text { Determinar se o uso pós- } \\
\text { operatório de nutrição enteral } \\
\text { enriquecida com arginina, } \\
\text { glutamina e ácidos graxos } \\
\text { ômega-3 influencia a } \\
\text { sobrevivência em pacientes } \\
\text { diagnosticados com câncer } \\
\text { de estômago }\end{array}$ & $\begin{array}{l}99 \quad \text { pacientes } \\
\text { submetidos à cirurgia } \\
\text { para câncer gástrico; } \\
\\
\text { Grupo } \\
(\mathrm{n}=45), \\
\begin{array}{l}\text { Grupo } \\
(\mathrm{n}=54)\end{array}\end{array}$ & $\begin{array}{l}\text { Glutamina, } \\
\text { arginina e } \\
\text { ácidos graxos } \\
\text { ômega-3 }\end{array}$ & $\begin{array}{l}\text { Grupo suplementado (EEN): no } \\
\text { pós-cirúrgico com Reconvan } 20 \\
\mathrm{ml} / \mathrm{h} \text { no dia } 1,50 \mathrm{ml} / \mathrm{h} \text { dia } 2,75 \\
\mathrm{ml} / \mathrm{h} \text { dia } 3 \text { e } 100 \text { ml } / \mathrm{h} \\
\text { posteriormente até } 7^{\circ} \text { dia. } \\
\text { Grupo controle: Peptisorb }\end{array}$ & 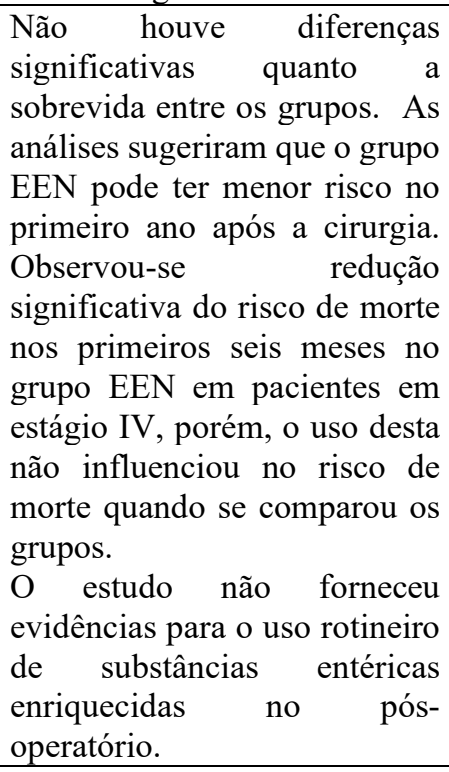 \\
\hline $\begin{array}{l}\text { Marano L, et } \\
\text { al., }(2013)^{15}\end{array}$ & $\begin{array}{l}\text { Ensaio clínico } \\
\text { randomizado } \\
\text { controlado }\end{array}$ & 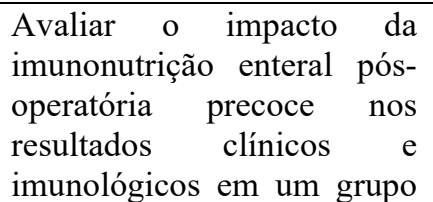 & $\begin{array}{l}109 \text { pacientes com } \\
\text { câncer gástrico } \\
\text { Grupo suplementado } \\
(\mathrm{n}=54)\end{array}$ & $\begin{array}{l}\text { Arginina, ácidos } \\
\text { graxos ômega-3 } \\
\text { e ácido } \\
\text { ribonucleico } \\
\text { (RNA) }\end{array}$ & $\begin{array}{l}\text { Grupo suplementado }(\mathrm{n}=54) \text { : } \\
\text { dieta enteral imuno-enriquecida- } \\
\text { IMPACT } \\
\text { Grupo controle }(\mathrm{n}=55) \text { : dieta } \\
\text { enteral padrão. }\end{array}$ & 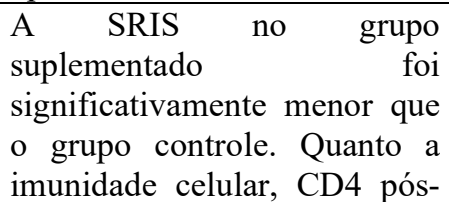 \\
\hline
\end{tabular}


Dietas imunomoduladoras em pacientes com câncer do trato gastrointestinal: Revisão integrativa Immunomodulatory diets in patients with gastrointestinal tract cancer: Integrative review

\begin{tabular}{|c|c|c|c|c|c|c|}
\hline & & $\begin{array}{l}\text { homogêneo de pacientes com } \\
\text { câncer gástrico submetidos à } \\
\text { gastrectomia total. }\end{array}$ & controle & & $\begin{array}{l}\text { A nutrição por jejunostomia foi } \\
\text { introduzida nos dois grupos } 6 \mathrm{~h} \\
\text { após a cirurgia até o } 7^{\circ} \text { dia de } \\
\text { pós-operatório. }\end{array}$ & $\begin{array}{l}\text { operatório e contagem de } \\
\text { células T diminuiu em ambos } \\
\text { os grupos, mas no grupo } \\
\text { suplementado a redução foi } \\
\text { significativamente maior em } \\
\text { comparação com o grupo } \\
\text { controle. } \\
\text { A imunonutrição enteral pós- } \\
\text { operatória precoce melhora } \\
\text { significativamente } \\
\text { resultados clínicos es } \\
\text { imunológicos em pacientes } \\
\text { submetidos à gastrectomia por } \\
\text { câncer gástrico }\end{array}$ \\
\hline $\begin{array}{l}\text { Nagano T, et } \\
\text { al., }(2013)^{16}\end{array}$ & $\begin{array}{l}\text { Ensaio clínico } \\
\text { randomizado } \\
\text { controlado }\end{array}$ & 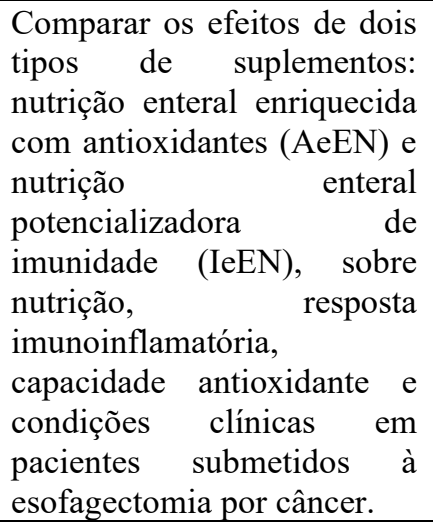 & $\begin{array}{l}20 \quad \text { pacientes } \\
\text { submetidos à } \\
\begin{array}{l}\text { esofagectomia por } \\
\text { câncer. }\end{array} \\
\text { Grupo AeEN }(\mathrm{n}=10) \\
\text { Grupo IeEN }(\mathrm{n}=10)\end{array}$ & $\begin{array}{l}\text { Arginina, ácidos } \\
\text { graxos ômega- } \\
3 \text { - } \\
\text { poliinsaturados } \\
\text { e nucleotídeos }\end{array}$ & $\begin{array}{l}\text { Grupo AeEN (n=10): } 800 \mathrm{ml} \text { de } \\
\text { Anom via oral por cinco dias } \\
\text { antes da cirurgia. Sete dias pós } \\
\text { cirúrgico } 400 \text { a } 1.600 \mathrm{ml} \text { foi } \\
\text { administrado com gastrostomia. } \\
\text { Grupo IeEN (n=10): } 750-1000 \\
\text { ml IMPACT via oral por cinco } \\
\text { dias antes da cirurgia. Sete dias } \\
\text { pós- cirúrgico } 500 \text { a } 1.500 \mathrm{ml} \text {, foi } \\
\text { administrado por gastrostomia }\end{array}$ & $\begin{array}{l}\text { A nutrição enteral (Anom) } \\
\text { nutriça enteral (Impact) } \\
\text { mostraram efeitos semelhantes } \\
\text { na nutrição, na reação imuno- } \\
\text { inflamatória, no estresse } \\
\text { oxidativo e nos resultados } \\
\text { clínicos após a esofagectomia } \\
\text { por câncer quando utilizados } \\
\text { no período perioperatório. }\end{array}$ \\
\hline $\begin{array}{l}\text { Van } \\
\text { Barneveld, et } \\
\text { al., }(2016)^{17}\end{array}$ & $\begin{array}{l}\text { Estudo } \\
\text { prospectivo } \\
\text { prévio } \\
\text { randomizado }\end{array}$ & $\begin{array}{l}\text { Comparar os benefícios da } \\
\text { nutrição enteral e parenteral } \\
\text { com a suplementação de } \\
\text { glutamina, arginina e } \\
\text { citrulina, em pacientes com } \\
\text { câncer retal avançado ou que } \\
\text { requer cirurgia agressiva. }\end{array}$ & $\begin{array}{l}123 \text { pacientes com } \\
\text { carcinoma retal, } \\
\text { localmente avançado } \\
\text { ou recorrente que } \\
\text { requerem cirurgia } \\
\text { retal de grande porte. } \\
\text { Grupo suplementado } \\
(\mathrm{n}=61) ; \\
\text { Grupo controle } \\
(\mathrm{n}=62)\end{array}$ & $\begin{array}{l}\text { Glutamina, } \\
\text { arginina e } \\
\text { citrulina }\end{array}$ & $\begin{array}{l}\text { Grupo de nutrição enteral: } \\
\text { receberam tubo } \\
\text { nasojejunalauto-migratório, } \\
\text { inseridas no pré-operatório. } \\
\text { Grupo de nutrição parenteral: } \\
\text { receberam um cateter via } \\
\text { jugular, enriquecida com } 200 \\
\text { mL de Depeptiven/dia para } \\
\text { garantir maior suprimento de } \\
\text { aminoácidos. } \\
\text { A nutrição suplementar EEN e } \\
\text { EPN foi fornecida no período de }\end{array}$ & $\begin{array}{l}\text { Verificou-se que } \\
\text { concentrações mais baixas de } \\
\text { glutamina e arginina foram } \\
\text { medidas no grupo enteral, } \\
\text { quando comparado ao grupo } \\
\text { parenteral, em que foi obtido } \\
\text { um resultado clínico melhor } \\
\text { dos aminoácidos. Conclui-se } \\
\text { que a suplementação com os } \\
\text { aminoácidos não obteve } \\
\text { resultados significativos, sem a } \\
\text { existência de qualquer relação }\end{array}$ \\
\hline
\end{tabular}




\begin{tabular}{|c|c|c|c|c|c|c|}
\hline & & & & & $\begin{array}{l}\text { cinco dias no pós-operatório. A } \\
\text { nutrição foi iniciada } 8 \mathrm{~h} \text { após a } \\
\text { cirurgia com } 500 \mathrm{~mL} / 24 \mathrm{~h} \text {. No } \\
\text { dia seguinte aumentou para } \\
1 \mathrm{~L} / 24 \mathrm{~h} \mathrm{e} \mathrm{no} 2^{\circ} \text { dia } 2 \mathrm{~L} / 24 \mathrm{~h} \text {. }\end{array}$ & $\begin{array}{l}\text { entre os efeitos benéficos } \\
\text { observados da alimentação } \\
\text { enteral e parenteral precoce. }\end{array}$ \\
\hline $\begin{array}{l}\text { Sultan, et al., } \\
(2012)^{18}\end{array}$ & $\begin{array}{l}\text { Estudo } \\
\text { prospectivo e } \\
\text { randomizado }\end{array}$ & $\begin{array}{l}\text { Elucidar se a nutrição enteral } \\
\text { enriquecida com PUFA } \\
\text { específico melhora o curso } \\
\text { pós-operatório de pacientes } \\
\text { com câncer de } \\
\text { esofagectomia. Comparando } \\
\text { uma dieta imunomoduladora } \\
\text { contendo EPA, GLA e } \\
\text { antioxidantes com dieta } \\
\text { isocalórica e isonitrógena. }\end{array}$ & $\begin{array}{l}92 \text { pacientes foram } \\
\text { requisitados, cinco } \\
\text { foram excluídos e } \\
\text { permaneceram } 87 \\
\text { indivíduos. } \\
\\
\text { Grupo suplementado: } \\
\text { (n=42); } \\
\text { Grupo controle: } \\
(\mathrm{n}=45)\end{array}$ & $\begin{array}{lr}\begin{array}{l}\text { Ácidos } \\
\text { ômega-3 }\end{array} & \text { graxos } \\
\text { 3FAs) } & \text { (O- }\end{array}$ & $\begin{array}{l}\text { O primeiro grupo de IED } \\
\text { recebeu Oxepa (alimento rico em } \\
\text { O-3FAs) com } 51 \mathrm{~g} / 100 \mathrm{ml} \mathrm{de} \\
\mathrm{EPA} \text { e } 22 \mathrm{~g} / 100 \mathrm{ml} \text { de DHA, } \\
\text { durante sete dias antes e após } \\
\text { cirurgia. } \\
\text { Grupo enteral (NEE) recebeu o } \\
\text { Ensure Plus (alimento entérico), } \\
\text { rico com } 5 \mathrm{kcal} / \mathrm{ml} \text { com 6- } \\
25 \mathrm{~g} / 100 \mathrm{ml} \text { de proteína, por sete } \\
\text { dias antes e após a cirurgia. } \\
\text { Grupo controle não recebeu } \\
\text { suporte nutricional pré- } \\
\text { operatório. }\end{array}$ & $\begin{array}{l}\text { Conclui-se que a } \\
\text { imunonutrição antes e após a } \\
\text { cirurgia não conferiu vantagem } \\
\text { no resultado clínico geral em } \\
\text { comparação com a c a a } \\
\text { alimentação enteral padrão } \\
\text { isocalórica e isonitrogênica. }\end{array}$ \\
\hline $\begin{array}{l}\text { Matsuda, } e t \\
\text { al., }(2017)^{19}\end{array}$ & $\begin{array}{l}\text { Estudo clínico } \\
\text { prospectivo } \\
\text { randomizado }\end{array}$ & $\begin{array}{l}\text { Examinar o efeito da } \\
\text { administração parenteral } \\
\text { ómega-3, e administração de } \\
\text { ácidos graxos nos níveis } \\
\text { plasmáticos de lactato após } \\
\text { gastrectomia em pacientes } \\
\text { com câncer gástrico. }\end{array}$ & \begin{tabular}{|lr}
26 & pacientes \\
agendados para \\
cirurgia de câncer \\
gástrico. \\
Grupo intervenção: \\
$(\mathrm{n}=12)$ \\
$\begin{array}{l}\text { Grupo controle; } \\
(\mathrm{n}=14)\end{array}$ \\
\end{tabular} & $\begin{array}{l}\text { Dieta } \\
\text { imunomodulado } \\
\text { ra enriquecida } \\
\text { com EPA, GLA } \\
\text { e antioxidantes } \\
\text { versus dieta } \\
\text { isocalórica e } \\
\text { isonitrógena. }\end{array}$ & $\begin{array}{l}\text { Todos os pacientes receberam } \\
\text { alimentação enteral contínua } \\
\text { dentro de } 48 \mathrm{~h} \text { após a cirurgia. A } \\
\text { taxa de administração de ambos } \\
\text { foi de } 10 \mathrm{ml} / \mathrm{h} \text {; aumentando em } \\
10 \mathrm{ml} / \mathrm{h} \text { a cada dois dias para } 30 \\
\mathrm{ml} / \mathrm{h} \text {. A alimentação enteral foi } \\
\text { reduzida para } 400 \mathrm{ml} / \mathrm{dia} \text { e } \\
\text { continuou por duas semanas. }\end{array}$ & $\begin{array}{l}\text { O estudo indica eficácia } \\
\text { potencial da introdução da } \\
\text { dieta imunomoduladora enteral } \\
\text { enriquecida com EPA, GLA e } \\
\text { antioxidantes em pacientes } \\
\text { submetidos à esofagectomia } \\
\text { torácica. }\end{array}$ \\
\hline $\begin{array}{l}\text { Makay, et al., } \\
(2011)^{20}\end{array}$ & $\begin{array}{l}\text { Estudo clínico } \\
\text { prospectivo } \\
\text { randomizado }\end{array}$ & $\begin{array}{l}\text { Examinar o efeito da } \\
\text { administração parenteral } \\
\text { ômega-3, e administração de } \\
\text { ácidos graxos nos níveis } \\
\text { plasmáticos de lactato após } \\
\text { gastrectomia em pacientes } \\
\text { com câncer gástrico. }\end{array}$ & 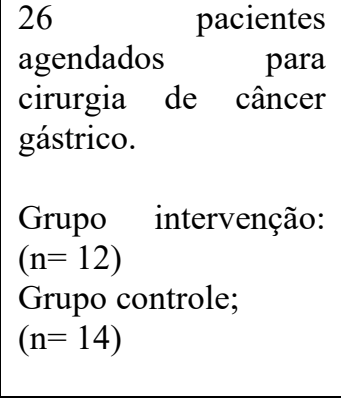 & $\begin{array}{l}\text { Ácidos graxos } \\
\text { Ômega-3 }\end{array}$ & $\begin{array}{l}\text { Grupo } 1 \text { recebeu nutrição } \\
\text { parenteral (NP) com w-6 FAs. } \\
\text { Grupo } 2 \text { recebeu w- } 6+\mathrm{w}-3 \text { FAs. } \\
\text { Todos receberam NP por cinco } \\
\text { dias no pós-operatório, de } \\
\text { acordo com um protocolo: } 3 \mathrm{~g} \\
\text { por } \mathrm{kg} \text { de peso corporal de } \\
\text { glicose e } 1,2 \mathrm{~g} / \mathrm{kg} \text { de } \\
\text { aminoácidose } 0,8 \mathrm{~g} / \mathrm{kg} \mathrm{w}-6 \mathrm{FAs} \text {, } \\
\text { foram fornecidos a ambos os }\end{array}$ & $\begin{array}{l}\text { Não foi evidenciado qualquer } \\
\text { vantagem evidente sobre a } \\
\text { imunonutrição pós-operatória } \\
\text { de rotina com w-3 FAs em } \\
\text { pacientes submetidos à } \\
\text { cirurgia gastrointestinal } \\
\text { superior para câncer gástrico. }\end{array}$ \\
\hline
\end{tabular}


Dietas imunomoduladoras em pacientes com câncer do trato gastrointestinal: Revisão integrativa Immunomodulatory diets in patients with gastrointestinal tract cancer: Integrative review

\begin{tabular}{|c|c|c|c|c|c|c|}
\hline & & & & & $\begin{array}{l}\text { grupos por meio de cateter } \\
\text { venoso central interno. }\end{array}$ & \\
\hline $\begin{array}{l}\text { Long, et al., } \\
(2013)^{21}\end{array}$ & $\begin{array}{l}\text { Estudo clínico } \\
\text { randomizado }\end{array}$ & $\begin{array}{l}\text { Investigar se a adição ômega- } \\
3 \text { ácidos graxos poli- } \\
\text { insaturados (PUFAs) para } \\
\text { nutrição enteral (NP) pode } \\
\text { reduzir a inflamação e } \\
\text { melhorar a função imune em } \\
\text { pacientes, após cirurgia de } \\
\text { câncer de esôfago. }\end{array}$ & $\begin{array}{l}60 \text { pacientes (entre } 36 \\
\text { e } 76 \text { anos) submetidos } \\
\text { à cirurgia de câncer de } \\
\text { esôfago. } \\
\text { Grupo controle: } \\
(\mathrm{n}=30) \\
\begin{array}{l}\text { Grupo experimental: } \\
(\mathrm{n}=30)\end{array}\end{array}$ & $\begin{array}{l}\text { Ácidos graxos } \\
\text { Ômega-3 } \\
\text { (PUFAs) }\end{array}$ & $\begin{array}{l}\text { Grupo controle }(\mathrm{n}=30) \\
\text { receberam nutrição parenteral } \\
\text { total, apenas com óleo de soja. } \\
\text { Grupo experimental }(\mathrm{n}=30) \\
\text { receberam ômega-3 PUFAs com } \\
\text { óleo de peixe e óleo de soja. } \\
\text { A dose de ômega-3 PUFAs } \\
\text { foram de } 0,17 \mathrm{~g} / \mathrm{kg} \text { durante os } \\
\text { sete dias após a cirurgia. }\end{array}$ & 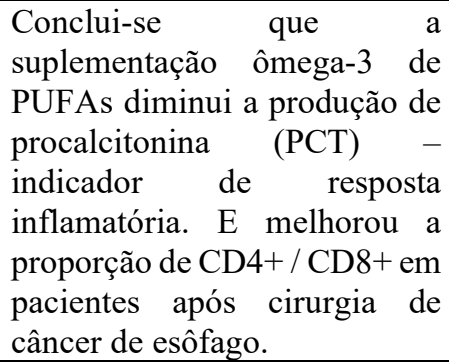 \\
\hline
\end{tabular}

Legendas: GIST- tumor estromal gastrointestinal; EN- nutrição enteral; AGC- câncer gástrico avançado; GFO- glutamina, fibra e oligossacarídeos; AeEN-nutrição enteral enriquecida com antioxidantes; IeEN-nutrição enteral potencializadora de imunidade; VO- alimentação via oral; Gln- glutamina; PT- proteínas; LIP- lipídios; CHO- carboidrato; EEN- nutrição enteral enriquecida; IgG- imunoglobulina G; IgM- imunoglobulina M; PCR- proteína C reativa; RNA-ácido ribonucleico; PUFAs ou FAs - ácido graxo poliinsaturado; PCT - procalcitonina; w-3 - ômega 3; w-6 - ômega 6; EEN ou NE - nutrição enteral; EPN ou PN - nutrição parenteral; IED - dieta imuno-estimulante; SIRS - Síndrome da resposta inflamatória sistêmica, GLA - gama-linolênico.

Fonte: Dados da pesquisa, 2020. 
A suplementação com imunonutrientes em pacientes oncológicos tem sido bastante estudada atualmente diante dos benefícios que a terapia imunomoduladora pode promover. Houve estudos que mostraram resultados positivos na terapia utilizada como a diminuição da inflamação com melhora na síndrome da resposta inflamatória sistêmica, melhora do estado nutricional reduzindo o risco de desnutrição, complicações pós-cirúrgicas e diminuição do tempo de internação. Entretanto, também observaram-se estudos que não evidenciaram diferença significativa ou resultados significativos da terapia imunomoduladora comparados à nutrição enteral padrão, devido a diferentes metodologias abordadas, dosagens administradas e período de intervenção diferentes.

Vale ressaltar que a dosagem da suplementação tem forte influência no resultado geral do tratamento, porém, ainda não há protocolos específicos de dosagens adequadas desses imunonutrientes (glutamina, arginina e ácidos graxos ômega - 3), devido ao mercado disponibilizar produtos considerados padrões e cada produto de nutrição enteral enriquecido possuir uma concentração diferente de cada imunonutriente.

O tempo de intervenção com terapia imunomoduladora também contribuiu para a diferença nos resultados. As intervenções nos estudos variaram de três a cinco dias antes, e de sete até quatorze dias após cirurgia. Tempo esse considerado dentro do recomendado pela ESPEN que é de cinco a sete dias e em até quatorze dias em casos de desnutrição, tanto no pré como no póscirúrgico, o qual possui recomendação nível $\mathrm{A}^{5}$.

\section{Discussão}

\section{Desnutrição em pacientes oncológicos}

A desnutrição ou caquexia é caracterizada pela perda ponderal excessiva de peso, anorexia, depleção do sistema imune e astenia; está associada à diminuição da resposta ao tratamento e à qualidade de vida do paciente, oferecendo assim maior risco de infecção pósoperatória e aumento da morbimortalidade. Seu grau e prevalência dependem do tipo de câncer, estágio do tumor, localização, das terapias utilizadas e da resposta do paciente. Tem como fatores mais comuns para seu desenvolvimento as alterações metabólicas, catabolismo intenso, estresse, dieta, além da oferta inadequada de nutrientes ${ }^{5,2,22}$.

Para avaliação do risco nutricional ou desnutrição em pacientes com câncer, é utilizada a Avaliação Subjetiva Global Produzida pelo Próprio Paciente (ASGPPP), um método que permite realizar uma avaliação nutricional do paciente, a fim de identificar sintomas de impacto nutricional. A mesma deve ser realizada em até 48 horas após a internação do paciente para avaliação do risco e assim facilitar a escolha da terapia nutricional adequada. Os pacientes que apresentarem risco ou desnutrição devem ser reavaliados de forma detalhada durante o período de pré e pós-operatório ${ }^{23,2}$.

Em média 15 a $80 \%$ dos pacientes oncológicos podem apresentar perda de peso involuntária e desnutrição. No câncer gastrointestinal, é comum alterações no processo de digestão e absorção dos alimentos, as quais podem levar a maior suscetibilidade para desnutrição e assim refletir de forma negativa na qualidade de vida e no prognóstico do paciente ${ }^{24}$.

Diante das alterações metabólicas causadas, os pacientes oncológicos que são submetidos a cirurgias do trato gastrointestinal, geralmente apresentam altas incidências de complicações, principalmente infecciosas, tanto durante o pós-operatório inicial como também ao longo do período de hospitalização ${ }^{15}$.

Dessa forma, a terapia nutricional deve ser iniciada de forma preferencial quando os pacientes ainda não estiverem gravemente desnutridos e quando os objetivos do tratamento forem manter ou melhorar a nutrição dos pacientes. Assim, o suporte nutricional deve ser oferecido a 
pacientes com risco de desenvolvimento de anorexia ou defeitos gastrointestinais devido aos efeitos colaterais decorrentes do tratamento. Pacientes gravemente desnutridos, que estão em tratamento ativo, devem receber oferta terapêutica nutricional de forma imediata ${ }^{25}$.

O início do uso da terapia nutricional envolve geralmente $o$ enriquecimento de alimentos e suplementos orais. Caso o paciente não possa deglutir o alimento, mas mantém o trato gastrointestinal funcionante, é recomendada a alimentação via enteral por sonda para garantir a ingestão de nutrientes ${ }^{6}$.

A atenção para dietas com Nutrientes imunomoduladores como glutamina, arginina, ácidos graxos omega-3 e nucleotídeos, aumenta cada vez mais pelos efeitos benéficos que exercem no sistema imunológico, quando comparados dietas enterais padrão; podendo ainda auxiliar no tratamento de pacientes com desnutrição, caquexia e câncer ${ }^{7,6}$.

Um estudo realizado com 78 pacientes com câncer gástrico avançado, submetidos à gastrectomia total, mostrou que no grupo suplementado com nutrição enteral imunologicamente melhorada houve melhora no estado nutricional com a síntese de proteínas, albumina, pré-albumina e transferrina, além da função imunológica, promovendo uma recuperação mais rápida do intestino e do sistema imune ${ }^{12}$.

\section{Nutrientes imunomoduladores no câncer}

A terapia imunomoduladora é uma abordagem bastante utilizada para fortalecimento das defesas imunológicas e para ajudar na redução de complicações do paciente. Define-se terapia imunomoduladora como fórmulas enterais padrão suplementadas com nutrientes imunomoduladores cuja função é melhorar a defesa imunológica, a função da barreira intestinal e reduzir a resposta inflamatória ${ }^{26}$.

Fortalecer as defesas imunológicas do paciente é uma abordagem útil para ajudar a reduzir complicações. Nutrientes como a glutamina, arginina, ácidos graxos ômega-
3, ácidos nucléicos e antioxidantes, podem agir na modulação de processos imunológicos e inflamatórios, como em queimaduras, traumas e cirurgias de grande porte e ainda melhorar os resultados clínicos $^{4}$.

Como forma de tratamento, a suplementação imunomoduladora fornece ao paciente hospitalizado melhora do seu quadro clínico, auxiliando a recuperação pós-operatória, reduzindo o desconforto abdominal e realizando a manutenção e função da barreira intestinal. Sendo assim, a glutamina é um aminoácido importante para recuperação da mucosa do intestino e fortalecimento da imunidade, utilizada neste estudo para reduzir os efeitos adversos no sistema imunológico ocasionados pelo tempo de internação e procedimentos quimioterápicos que $\mathrm{o}$ paciente é submetido ${ }^{12}$.

Por outro lado, a introdução da nutrição enteral é meio de acesso utilizado para evitar a desnutrição ocasionada nos pacientes oncológicos. Em um estudo realizado no Hospital Popular de Liaocheng, foram avaliados 46 pacientes com enterite por radiação, durante o período de internação, o grupo estudado foi suplementado com glutamina, óleo de peixe e Peptisorb, que obtiveram melhor tolerância à nutrição enteral, menor taxa de flatulência e diarreia em comparação ao grupo controle. Desse modo, a glutamina juntamente com os outros imunonutrientes, auxiliou na recuperação de células epiteliais, melhor resposta da função imune intestinal e diminuição da lesão de oxidação intestinal $^{27}$.

A glutamina é um aminoácido condicionalmente essencial, sintetizada principalmente a partir do catabolismo de aminoácidos de cadeia ramificada no músculo esquelético. Atua na síntese de nucleotídeos, citocinas, proteínas, proliferação de células do sistema imunológico, além de ser fonte de energia para células intestinais e também prevenir atrofia da mucosa, adesão e a translocação bacteriana. É o principal combustível para 
linfócitos e macrófagos e age como precursora de glutationa, sendo responsável pelo sistema de defesa antioxidante. É o aminoácido mais abundante no organismo, mas que em situações de estresse, cirurgias, traumas, queimaduras, que levam ao consumo superior à síntese, é necessária a suplementação a fim de prevenir processos inflamatórios ${ }^{4,5,26}$.

A arginina é um aminoácido não essencial que exerce um papel na síntese do óxido nítrico, que regula a expressão gênica e estimula a imunidade mediada por células. Ela estimula a secreção de hormônios como o de crescimento, glucagon e insulina, os quais possuem efeito imunomodulatório. A arginina atua ainda sobre a proliferação e maturação de linfócitos $\mathrm{T}$, pode reduzir a produção de mediadores pró-inflamatórios (IL-1, IL-6 e FNT- $\alpha$ ), também pode melhorar a imunidade celular (linfócitos CD4, CD8), e acelerar o crescimento tecidual após trauma ou infecção. ${ }^{4,26}$

Os ácidos graxos ômega-3 são considerados essenciais, e fontes de docosahexaenóico (DHA) e ácido eicosapentanóico (EPA), os quais são derivados do óleo de peixe. Exercem funções importantes na estrutura das membranas e processos vitais, pois tem a capacidade de melhorar a flexibilidade da membrana celular. Exerce efeitos antiinflamatórios pela redução da agregação plaquetária e do potencial pró-inflamatório. Os ácidos graxos ômega-3 ainda possuem capacidade de suprimir o crescimento tumoral por meio da apoptose celular, e também reduzir os efeitos da resposta inflamatória sistêmica. A suplementação ainda reduz a síntese de prostaglandinas (PG) e tromboxanos A2 (TXA2) ${ }^{5,26}$.

Utilizar fórmulas imunomoduladora na avaliação dos riscos de complicações no pré, peri e pós-operatório tem demonstrado acurácia significativa, na recuperação de pacientes submetidos à cirurgia de câncer gastrointestinal. De acordo com o estudo, quando as formulações possuem aminoácidos como arginina, ácidos graxos ômega-3 e nucleotídeos a eficácia no tempo de internação e recuperação é mais rápida. A adoção dessa terapia nutricional vem sendo fortemente inserida nesses pacientes, como forma de prevenir complicações durante $o$ processo de recuperação, infecções e reduzir custos hospitalares ${ }^{28}$.

Em cirurgias de grande porte, alguns aminoácidos tornam-se cruciais para garantir a homeostase do corpo e também evitar que o estresse oxidativo ou até mesmo o estado catabólico do paciente entre no estado crítico de trauma. A glutamina em associação com a arginina obtém papel importante nesse processo, pois a ativação do Óxido Nítrico acelera a vasodilatação, neoangiogênese e fortalece o sistema imune, sendo adequadas na cicatrização e anastomose intestinal ${ }^{17}$.

Outra forma terapêutica atualmente utilizada é administração dos antioxidantes, que atuam no combate do câncer intestinal inibindo a hiperproliferação epitelial gástrica, responsável por induzir a necrose tumoral. Por conseguinte, o ácido ascórbico e beta-caroteno são importantes aliados que reduzem o Fator de Necrose Tumoral (TNF) no intestino, induzido pelo $\mathrm{H}$. pylori, responsável pelo câncer gástrico e gastrite atrófica ${ }^{29}$.

\section{Terapia imunomoduladora na resposta inflamatória e imunológica}

É inevitável a perda involuntária de peso em pacientes que são diagnosticados com câncer gastrointestinal, pois é recorrente a depleção da reserva de energia corporal. Para prevenir maior perda de peso, minimizar os efeitos deletérios de longos períodos em jejum prolongado no Peri operatório e reduzir as infecções no pósoperatório, a terapia nutricional é acionada, almejando a recuperação aprimorada do paciente. Nesse sentido, o aporte nutricional enteral com imunomoduladores é cada vez mais utilizado pelos profissionais da saúde $^{30}$.

A ingestão inadequada por mais de 14 dias no pós-operatório, resulta em maior risco de mortalidade dos pacientes, isso é 
ocasionado pela baixa ingestão de proteínas e calorias, aumentando o período de internação e aumentando a prevalência de desnutrição. A dosagem adequada de glutamina, ômega-3 e arginina, minimiza o impacto nutricional e metabólico. De acordo com o estudo observacional em alguns pacientes hospitalizados, as diferenças foram significativas entre aqueles que eram suplementados e o grupo controle, pois as complicações evidenciadas eram mínimas e a recuperação foi rápida e efetiva, havendo diminuição do trauma cirúrgico $^{31}$.

Em um estudo realizado com suplementação de dieta imunomoduladora de arginina, ácidos graxos ômega -3 e RNA em 109 pacientes com câncer gástrico, notou-se que houve melhora na imunidade e redução da Síndrome da resposta inflamatória sistêmica (SRIS) nos pacientes suplementados em relação à nutrição enteral padrão. Outro estudo com 78 pacientes cirúrgicos de gastrectomia total mostrou que a suplementação de arginina e glutamina foi positiva na melhora do sistema imune e promoveu menor tempo de internação nos pacientes ${ }^{12,15}$.

O papel da nutrição não se baseia somente em fornecer o aporte adequado de proteínas, lipídeos e carboidratos aos pacientes, pelo contrário, o principal objetivo é fortalecer o sistema imunológico, restaurar a resposta metabólica a agentes infecciosos e atender as necessidades fisiológicas corporais. Portanto, a normalização da ingestão alimentar em conjunto com a nutrição enteral ajuda na recuperação de peso e aquisição da imunidade no paciente hospitalizado, isso confirma que a via enteral de alimentação tem mais eficácia comparado a nutrição parenteral e jejunal. As fórmulas moduladoras contendo nucleotídeos, antioxidantes, ômega-3 e aminoácidos, são considerados o padrão ouro, e sua adoção tem mostrado resultados positivos no tratamento dos pacientes ${ }^{32}$.

\section{Conclusão}

Conclui-se com base nos resultados evidenciados, que os efeitos da suplementação enteral no pré e pósoperatório com os imunonutrientes: ácidos graxos ômega-3, glutamina, arginina, e outros nutrientes (antioxidantes (EPA e GLA), fibras e ácido ribonucleico), contribuem positivamente na recuperação dos pacientes oncológicos, através da redução do catabolismo, diminuição da resposta inflamatória e da desnutrição, proporcionado melhora no estado nutricional e do sistema imunológico, além de ainda reduzir o tempo de internação hospitalar dos pacientes.

Sugere-se que sejam realizados novos estudos, com maior número de participantes, sobre os efeitos da suplementação com dietas imunomoduladoras, para promover a geração das evidências científicas necessárias para estabelecimento de protocolos de suplementação para casos cirúrgicos de pacientes que apresentam neoplasias do trato gastrointestinal.

\section{Referências}

1. Brasil. Ministério da saúde. Instituto Nacional do Câncer. Estimativa 2020:Incidência de câncer no Brasil. Rio de Janeiro: INCA; 2019. Disponível em https://www.inca.gov.br/sites/ufu.sti.inca.local/files//media/document//estimativa-2020incidencia-de-cancer-no-brasil.pdf. Acesso em 24 abr de 2020.

2. Barbosa LBG, Fortes RC, Toscano BAF. Impacto de fórmulas enterais imunomoduladoras em pacientes com câncer do trato gastrointestinal enteral: uma revisão da literatura. J Health Sci Inst. 2017;35(1):49-54. 
3. Sociedade Brasileira de Nutrição Parenteral e Enteral. Diretriz BRASPEN de terapia nutricional no paciente com câncer. BRASPEN J. 2019; 34.Supl 1: 2-32.

4. Ma C, Tsai H, Su W, Sun L, Shih Y, Wang J. Combination of arginine, glutamine, and omega-3 fatty acid supplements for perioperative enteral nutrition in surgical patients with gastric adenocarcinoma or gastrointestinal stromal tumor (GIST): A prospective, randomized, double-blind study. J Postgrad Med. 2018; 64:155-163.

5. Carmo SG, Fortes RC. Efeitos do uso de fórmulas imunomoduladoras em pacientes cirúrgicos portadores de câncer do trato gastrointestinal. Rev. Cient. Sena Aires. 2019; $8(1): 87-102$.

6. Souza JÁ, Gallon WC. Impacto do uso de dieta imunomoduladora e dieta enteral em adultos, durante a quimioterapia e radioterapia em pacientes com câncer de cabeça e pescoço: uma revisão da literatura. BRASPEN J. 2017; 32 (3): 273-81.

7. Barbosa MV, Queiroz FM, Pinho NB, Martucci RB.Impacto do Uso de Dieta Imunomoduladora em Pacientes com Câncer Colorretal Submetidos a Cirurgias Eletivas com Abreviação de Jejum Pré-operatório. Revista Brasileira de Cancerologia. 2015; 61(3): 217 225.

8. Mariette, C. Immunonutrition. Journalof Visceral Surgery. 2015; 152, 14 17. doi:10.1016/s1878-7886(15)30005-9

9. Beyea SC, Nicoll LH. Writing an integrative review.AORN journal. 1998;67(4).

10. da Costa Santos CM, de Mattos Pimenta CA, Nobre MRC. A estratégia PICO para a construção da pergunta de pesquisa e busca de evidências. Revista Latino-Americana de Enfermagem.2007; 15(3).

11. Moher D, Altman DG, Liberati A, Tetzlaff J. PRISMA statement. Epidemiology.2008; 22(1):128.

12. Liu H, Ling W, Shen ZY, Jin X, Cao H. Aplicação clínica da nutrição enteral imunologicamente aprimorada em pacientes com câncer gástrico avançado após gastrectomia total. Journal of Digestive Diseases. 2012; 13(8): 401-406.

13. Abe T, Hosoi T, Kawai R, Uemura N, Higaki E, An B, et al. A suplementação enteral perioperatória com glutamina, fibra e oligossacarídeo reduz o estresse cirúrgico pósoperatório precoce após a esofagectomia para câncer de esôfago. Esôfago. 2018. Doi: 10.1007 / s10388-

14. Klek S, Scislo L, Walewska E, Choruz R, Galas A. Enriched enteral nutrition may improve short term survival in stage IV gastric cancer patients, randomized controlled trial, Nutrition. 2016. Doi: 10.1016/j.nut.2016.03.016.

15. MaranoL, PorfidiaR, Pezzella M,Grassia M,Petrillo M,Esposito G, et al. Clinical and Immunological Impact of Early Postoperative Enteral Immunonutrition After Total 
Gastrectomy in Gastric Cancer Patients: A Prospective Randomized Study. Ann SurgOncol, 2013.Doi 10.1245/s10434-013-3088-1

16. Nagano T, Fujit H, Tanaka T, Matono S, Murata K, Ishibashi N, et al. A randomized controlled trial comparing antioxidant-enriched enteral nutrition with immune-enhancing enteral nutrition after esophagectomy for cancer: a pilot study. Surg Today, 2012. Doi $10.1007 / \mathrm{s} 00595-012-0424-1$

17. Van Barneveld KWY, Smeets BJJ, Heesakkers FFBM, Bosmans JWAM, Luyer MD, Wasowicz D, et al. Beneficial Effects of Early Enteral Nutrition After Major Rectal Surgery. Critical Care Medicine. 2016; 44(6): e353-361.

18. Sultan J, Griffin SM, Di Franco F, Kirby JA, Shenton BK, Seal CJ, et al. Ensaio clínico randomizado de nutrição enteral suplementada com ácido graxo ômega-3 versus nutrição enteral padrão em pacientes submetidos à cirurgia de câncer esofagogástrico. British Journal of Surgery. 2012; 99(3): 346-355.

19. Matsuda Y, Habu D, Lee S, Kishida S, Osugi H. Enteral Diet Enriched with $\omega-3$ Fatty Acid Improves Oxygenation After Thoracic Esophagectomy for Cancer: A Randomized Controlled Trial. World Journal of Surgery. 2017; 41(6): 1584-1594.

20. Makay O, Kaya T, Firat O, Sozbilen M, Caliskan C, Gezer G, et al. $\omega$-3 Fatty Acids Have No Impact on Serum Lactate Levels After Major Gastric Cancer Surgery.Journal of Parenteral and Enteral Nutrition. 2011; 35(4):488-492.

21. Long H, Yang H, Lin Y, Situ D, Liu W. Fish Oil-Supplemented Parenteral Nutrition in Patients Following Esophageal Cancer Surgery: Effect on Inflammation and Immune Function. NutritionandCancer. 2013; 65(1):71-75.

22. Smiderle CA, Gallon CW. Desnutrição em oncologia: revisão de literatura. RevBrasNutrClin. 2012; 27 (4): 250-6.

23. Damo CC, Pelissaro E, Cibulski TP, Calcing A, Basso T. Câncer gastrintestinal: impacto nutricional em pacientes hospitalizados. BRASPEN J. 2016; 31 (3): 232-6.

24. Stangherlin L, Barros TP, Bongiolo AM, Silva MA, Castro K, Ceretta LB, et al. Risco nutricional em pacientes com câncer do trato gastrointestinal: métodos diagnósticos. Ciência e saúde. 2018; 11(4):204-210.

25. Arends J, Bachmann P, Baracos V, Barthelemy N, Bertz H, Bozzetti F, et al. Diretrizes ESPEN sobre nutrição em pacientes com câncer. Nutrição clínica. 2017; 36(1):11-48.

26. Fortes, RC; Waitzberg DL. Efeitos da imunonutrição enteral em pacientes oncológicos submetidos à cirurgia do trato gastrintestinal. Rev Bras Nutr Clin. 2011; 26(4):255-63.

27. Shao F, Xin F, Yang C, Yang D, Mi Y, Yu J, et al. The Impact of Microbial Immune Enteral Nutrition on the Patients with Acute Radiation Enteritis in Bowel Function and Immune Status. Cell Biochemistry and Biophysics. 2013; 69(2): 357-361. 
28. Chevrou-Séverac, H, Pinget C, Cerantola Y, Demartines N, Wasserfallen J, Schäfer M. Cost-effectiveness analysis of immune-modulating nutritional support for gastrointestinal cancer patients. Clinical Nutrition. 2014; 33(4): 649-654.

29. Toh JWT, Wilson RB. Pathways of Gastric Carcinogenesis, Helicobacter pylori Virulence and Interactions with Antioxidant Systems, Vitamin C and Phytochemicals. International Journal of Molecular Sciences. 2020; 21(17): 6451.

30. Garla P, Waitzberg DL, Tesser A. Nutritional Therapy in Gastrointestinal Cancers. Gastroenterology Clinics of North America. 2018; 47(1): 231-242.

31. Sandrucci S, Beets G, Braga M, Dejong K, Demartines N. Perioperative nutrition and enhanced recovery after surgery in gastrointestinal cancer patients. A position paper by the ESSO task force in collaboration with the ERAS society (ERAS coalition). European Journal of Surgical Oncology. 2018; 44(4), 509-514.

32. Luo Z, Wang J, Zhang Z, Li H, Huang L, Qiao Y, et al. Efficacy of Early Enteral Immunonutrition on Immune Function and Clinical Outcome for Postoperative Patients With Gastrointestinal Cancer. Journalof Parenteral and Enteral Nutrition. 2017;

014860711771543. doi:10.1177/0148607117715439

\section{Como citar este artigo:}

Guimarães TASF, Silva LCS, Sales ALCC. Dietas imunomoduladoras em pacientes com câncer do trato gastrointestinal: Revisão integrativa. Rev. Aten. Saúde. 2021; 19(69):231-246. 